\title{
Sense of Coherence Moderates the Relationship between Social Capital and Oral Health-Related Quality of Life in Schoolchildren: A 10-Year Cohort Study
}

\author{
Jessica Klöckner Knorst \\ Universidade Federal de Santa Maria \\ Bruna Brondani \\ Universidade Federal de São Paulo \\ Bruno Emmanuelli \\ Universidade Federal de Santa Maria \\ Fernanda Tomazoni \\ Universidade Federal de Santa Maria \\ Mario Vianna Vettore ( $\square$ mario.vettore@uia.no) \\ University of Agder \\ Thiago Machado Ardenghi \\ Universidade Federal de Santa Maria
}

\section{Research Article}

Keywords: Children, Moderating effect, Oral Health, Quality of life, Sense of coherence, Social Capital.

Posted Date: January 25th, 2022

DOI: https://doi.org/10.21203/rs.3.rs-1277467/v1

License: (c) (i) This work is licensed under a Creative Commons Attribution 4.0 International License.

Read Full License

Version of Record: A version of this preprint was published at Health and Quality of Life Outcomes on April 2nd, 2022. See the published version at https://doi.org/10.1186/s12955-022-01965-3. 


\section{Abstract}

Background: This study aimed to evaluate the moderating effect of sense of coherence (SOC) on the relationship between social capital and oral health-related quality of life (OHRQoL) among schoolchildren.

Methods: A cohort study was conducted in the city of Santa Maria, Brazil, involving children aged 1-5 years at baseline who were reassessed after 10 years in adolescence (11-15 years-old). Social capital was assessed at baseline and follow-up through social networks and social trust. Sense of coherence scale (SOC-13) and the short form of the Child Perceptions Questionnaire 11-14 (CPQ11-14) were measured at 10-years follow-up. Demographic and socioeconomic characteristics, and dental caries were also evaluated. Moderating effect of SOC on the relationship between social capital and OHRQoL was tested using multilevel adjusted Poisson regression analysis and simple slope test.

Results: From the 639 subjects assessed at baseline, 429 were reassessed at follow-up (cohort retention rate $67.1 \%$ ). Moderate and high levels of SOC demonstrated a moderating effect on the relationship between social capital and OHRQoL. Among individuals who presented low social capital at baseline and follow-up, those who had high SOC reported, respectively, an impact $64 \%$ and $70 \%$ lower on OHRQoL when compared to those with low SOC. The greatest margin effect was observed in individuals with low social capital and low SOC at follow-up $(24.25 ; \mathrm{p}<0.05)$.

Conclusion: Our findings suggest that SOC moderates the negative impact of low social capital on poor OHRQoL in schoolchildren.

\section{Introduction}

Oral health inequalities remain a worldwide public health problem [1]. Currently, the focus is beyond the clinical measures of the dental diseases, and the patient's self-perception has been considered, especially on how oral health conditions affect their well-being and quality of life [2]. In this context, oral healthrelated quality of life (OHRQoL) measures have been widely advocated as an adjunct to clinical parameters in public policy planning and in the assessment of oral health strategies [3]. Clinical and socioeconomic conditions have been associated with OHRQoL [4,5]. In addition, contemporary approaches recognize the importance of the salutogenic model [6] and social capital [7] on planning oral health promotion actions and strategies to enhance OHRQoL.

Social capital has been described as the characteristics of the social structure, such as levels of trust and reciprocity, or individual social networks that act as resources accessed by individuals that can facilitate collective action $[8,9]$. High social capital may act as a protective factor on oral health buffering the effects of stress through the perception of mutual social support, as well as through feelings of security and belonging [10]. Other individual resources, such as sense of coherence (SOC), can also interact with a person's coping style and social capital $[11,12]$. Moreover, psychosocial mechanisms, including SOC, are 
central elements in the theoretical pathways developed to explain the relationship between social capital and oral health $[10,11]$.

SOC is defined as a global orientation that allows people to manage stress, identify their internal and external environments and find solutions for their health [6]. In this sense, SOC variations may explain why some individuals remain healthy even after experiencing stressful circumstances in life [6]. SOC has been associated with different aspects of health and disease. For instance, individuals with high SOC had less dental caries and dental pain [13], as well as better self-perceived health and better OHRQoL [14]. Previous studies have shown a moderating effect of SOC on the association between general quality of life and OHRQoL even when clinical conditions and symptoms were considered [14,15]. In this context, SOC might be an important psychosocial factor that can act as a moderator on the relationship between social capital and oral health outcomes.

The relationship between social life the characteristics, SOC and OHRQOL in children and adolescents has been demonstrated $[5,11,16]$. However, to our best knowledge, the association between social capital and OHRQoL considering the moderating effect of SOC in these age groups has not yet been explored. Children is a relevant population to investigate the above-mentioned links since $S O C$ is under development until early adulthood [6]. In addition, SOC can be an important ally to promote effective strategies to improve oral health. Thus, this study aimed to evaluate whether SOC modifies the association between social capital and OHRQoL from childhood to adolescence. We hypothesize that adolescent's OHRQoL are influence by low levels of social capital during childhood and adolescence according to different levels of SOC. It was anticipated that individuals with low social capital and high SOC would have better OHRQoL than those with low social capital and low SOC.

\section{Methods}

\section{Ethical aspects}

This project was approved by the Research Ethics Committee (CEP) of the Federal University of Santa Maria (protocol CAAE 11765419.1.0000.5346). All participants agreed to participate in the study and their parents signed an informed consent form in both phases of the study.

\section{Study design and participants}

This is a cohort study with 10 years of follow-up. Baseline (T1) collection was carried out in 2010 during the National Children's Vaccination Day in Santa Maria, Brazil. The estimated population of the city in 2010 was 263,403 inhabitants, which included 27,520 children up to 5 years old. The recruitment of the sample occurred in all 15 healthcare centres that had a dental office distributed in different neighbourhoods of the city. A systematic approach was adopted to select the children in the vaccination row. About 639 children up to 5 years old were evaluated. Additional information about the sample selection process is available elsewhere [17]. 
The cohort was followed and participants were reassessed in 2012 (2 years), 2017 (7 years), and 2020 (10 years). This study used data from baseline (T1) and 10-year follow up (T2). Data collection of the latter period was conducted between October 2019 and January 2021. Due to the COVID-19 pandemic, data collection at T2 was interrupted from March to September 2020 [18]. At T2, adolescents were searched at schools where they were enrolled, through telephone calls, and, if necessary, through online social networks such as WhatsApp and Facebook.

A post hoc power calculation considering alpha error probability of 0.05 , mean score of CPQ11-14 of 7.6 (SD 6.3) for the non-exposed group (high SOC), and mean score of 19.5 (SD 10.3) for the exposed group (low SOC), resulted in a sample power of $100 \%$.

\section{Data collection and variables}

Data was collected at the dental office of the healthcare centres at T1 and at the participant's homes or schools at T2 through clinical examinations and interviews using a structured questionnaire, following the international protocol for health surveys [19-22].

Social capital was evaluated at T1 and T2. In the former period, social capital was measured considering parents/legal guardians social networks using the following questions: a) "How often have you visited friends and neighbours in the last 12 months?"; b) "How often have you visited family members in the last 12 months?"; and c) How often do you participate in group religious activities, with the following response options: (0) at least once a month; (1) less than once a month or never. Social capital was evaluated through adolescent social networks and social trust at T2, using the following questions: a) "How often do you participate in group religious activities" (0) at least once a month or (1) less than once a month or never; b) "Do you participate in any group volunteer work?" (0) yes or (1) no and c) "Do you think your friends and neighbours are trustworthy?" (0) yes or (1) no. The items used to assess social capital at T1 and T2 are considered reliable proxies of social capital according to the literature $[5,23]$. Participants were classified as with high social capital (at least one type of social network or trust) or low social capital (absence of any type of network or trust) for analytical purposes as previously suggested $[24,25]$.

OHRQoL was assessed at T2 using the short version of the Child Perceptions Questionnaire 11-14 (CPQ11-14). The questionnaire was previously adapted and culturally transcribed for 5-years-old Brazilian children [20]. The short version of CPQ11-14 is composed of 16 questions, grouped into 4 domains: oral symptoms, functional limitation, social well-being, and emotional well-being. Each item is followed by a five-point Likert score: (0) "never"; (1) "once or twice", (2) "sometimes", (3) "often"; and (4) "every day/almost every day". OHRQoL scores are computed by summing code responses with a final score ranging from 0 to 64 . The higher the score, the worse the OHRQoL.

Adolescent SOC was assessed according to the Brazilian short version of the SOC-13 scale, originally developed by Antonovsky $(1987)[6,21]$. The questions are divided into three components: understandability, manageability, and meaning. The response options follow a 5-point Likert scale 
varying from 1 to 5 . The item codes are added to obtain the final score, which can vary from 13 to 65 . Higher scores indicate stronger levels of SOC. For data analysis, SOC was categorized as low (mean - 1 $\mathrm{SD})$, moderate (mean), and high (mean $+1 \mathrm{SD}$ ), according to previous literature [15].

Sociodemographic characteristics and dental caries were measured at baseline as possible confounders. Demographic characteristics included sex (girls or boys) and age (in complete years). Skin colour was evaluated using the criteria proposed by the Brazilian Institute of Geography and Statistics (IBGE) [26] and dichotomized into whites or on-whites. Maternal education was assessed according to years of schooling completed with approval and dichotomized into $<8$ years (up to primary school) or $\geq 8$ years (incomplete secondary school or more). Monthly family income in the previous month was collected and categorized as $>1$ Brazilian minimum wage (BMW) or $\leq 1 \mathrm{BMW}$. One BMW corresponded to 200 USD when the data was collected. Dental caries was assessed by the diagnostic criteria of the International Caries Detection and Assessment System (ICDAS) [22]. The number of teeth with untreated dental caries (ICDAS code 3, 5, or 6) was considered in the analysis. Surfaces with ICDAS stages 0, 1, 2 and 4 were classified as caries free. The dental exams were performed under artificial light, using a plain dental mirror, periodontal probe (CPI; "ballpoint") and gauze. The examiners were previously trained and calibrated (Kappa >0.70).

\section{Statistical analysis}

Data analysis was performed using STATA 14.0 statistical software (StataCorp. 2014. Stata Statistical Software: Release 14.0. College Station, TX: StataCorp L). All analyses were performed considering the sample weight ('svy') for complex data samples. The comparisons between participants who were assessed at follow up and dropouts, and between individuals assessed before and during the COVID-19 pandemic were evaluated by the chi-square test (qualitative variables) and the t-test (quantitative variables).

The study outcome was OHRQoL measured through the CPQ11-14 total scores. Unadjusted and adjusted Multilevel Poisson regression analysis was performed to evaluate the moderating effect of SOC on the relationship between social capital and OHRQoL. Moderation effects occur when the relationship between two variables vary according to a third variable, which is referred as the moderator variable. The effect of a moderating variable is statistically characterized as interaction; that is, a variable that affects the direction and/or strength of the association between the dependent and independent variables [27]. The logic map of the moderation effects is presented in Figure 1. The interaction in different categories was considered as follows: $0=$ low social capital $\times$ low SOC; $1=$ high social capital $\times$ low SOC; $2=$ high social capital $x$ high SOC; and $3=$ low social capital $x$ high SOC). Sociodemographic characteristics and dental caries variables with $p \leq 0.20$ in the unadjusted analysis were included in the adjusted model as possible confounders. The multilevel structure of analysis considered individuals (level 1) nested into 15 neighbourhoods (level 2). The results are presented in Ratio Ratio (RR) and 95\% confidence intervals $(95 \% \mathrm{Cl})$. 
The simple slope test was conducted afterwards once the hypothesized moderation effects were statistically significant to obtain the simple margins of predicted values by each level of the categorical moderator. This procedure allows the calculation of the conditional effect of social capital on OHRQoL according to SOC levels (moderator), generating a confidence interval and p-values [27]. A significance level of 0.05 was considered.

\section{Results}

Of the 639 subjects assessed at baseline, 429 were reassessed at 10-years follow-up (cohort retention rate $=67.1 \%)$. The reasons for losses to follow-up were impossibility of finding the adolescent $(n=184)$; move to another city $(n=19)$; or refusal to participate $(n=7)$. There were no significant differences of characteristics between individuals who completed the 10-years follow up and dropouts, nor between those evaluated before and during the COVID-19 pandemic ( $p>0.05)$.

Table 1 reports the descriptive characteristics of the sample. The sample was balanced between boys and girls, and most individuals reported white skin colour in both assessments. The mean age was 2.8 (SE 0.1) and 12.5 (SE 0.1) years old at baseline and follow-up. Most individuals presented monthly family income higher than $1 \mathrm{BMW}(70.8 \%)$ and mothers with more than 8 years of schooling at $\mathrm{T} 1$. The majority of participants presented high levels of social capital at T1 and T2, and about $7.9 \%$ of the sample presented low SOC at T2. The mean of CPQ11-14 total scores at follow-up was 11.2 (SE = 0.6).

Table 2 shows the multilevel unadjusted analysis considering the interaction of social capital at T1 and T2 and SOC at T2 on CPQ11-14 total scores at follow-up. In the crude analysis, individuals with low social capital at T1 (RR 1.16 95\% Cl 1.08-1.24) and at T2 (1.09; 95\% Cl 1.02-1.17) greater likely likelihood of poor OHRQoL. When these variables were included concomitantly in the model, they remained associated with the outcome $(p<0.05)$. Individuals with high SOC were more likely to report better OHRQoL (RR $0.39 ; 95 \% \mathrm{Cl} 0.36-0.46$ ). The different categories of the interaction terms social capital $\mathrm{x}$ SOC were associated OHRQoL considering low social capital and low SOC as the reference category.

The results of the moderation analysis after adjustment for confounders are presented in Table 3 . In general, moderate and high levels of SOC demonstrated a moderating effect on the relationship between social capital and OHRQoL. Among individuals who presented low social capital at T1 and T2, those who had higher SOC reported, respectively, an impact $64 \%$ and $70 \%$ lower on OHRQoL than those with low SOC. Among those with high social capital, regardless of their levels of SOC, the impact on OHRQoL was also lower when comparing to their counterparts (low social capital and low SOC).

Figures 2 and 3 presents the predictive marginal effects between social capital at T1 and T2 and CPQ1114 total scores according to different levels of SOC. According to the figures, the differences in predictive margins are visible only considering high levels of social capital at follow-up (cross-sectional interaction). However, the simple slope test (Table 4) indicated that the negative effects of low social capital on OHRQoL were statistically significant across different levels of SOC levels (low, moderate, and high) in 
both assessments (T1 and T2). The greatest margin effect was observed in individuals with low social capital and low SOC at T2 $(24.25 ; \mathrm{p}<0.05)$.

\section{Discussion}

This study aimed to evaluate the moderating effect of SOC on the association between social capital and OHRQoL. Our findings confirm the conceptual hypothesis that high SOC could attenuate the impact of low social capital on poor OHRQoL. In addition, the greatest moderation effect of SOC was observed in the interaction with social capital at follow-up. Despite the relationship between the characteristics of social life, SOC and OHRQOL in children and adolescents has already been researched $[5,11,15]$, such association considering the moderating effect of SOC has not been explored yet.

Considering the predictor variables separately, individuals with low social capital at baseline and at follow-up presented poorer OHRQoL at follow-up. This finding corroborates previous cross-sectional and cohort studies $[5,15,28]$. In our study, social capital was measured through proxies such as social networks and perception of trust. Thus, the present findings can be explained since individuals with more social networks and trust are subject to peer and more likely to adopt healthy behaviours that may influence OHRQoL. Moreover, these individuals are more likely to use dental services, which in turn can be related to better OHRQoL $[10,29]$. Greater social capital can also benefit health acting as a protective factor buffering the effects of stress through feelings of security, belonging, and social support, and consequently impacting on self-perceived health and quality of life $[10,29]$. Thus, individuals with low levels of social capital tend to report more oral impacts on their quality of life.

Among individuals with low social capital, those with moderate and high levels of SOC showed lower odds of worse OHRQoL than those with low SOC. Previous studies have shown a moderating effect of SOC on general and OHRQoL, considering other predictors, such as the need for dental prostheses and dental caries $[14,21]$. Furthermore, it has been suggested that SOC interacts with a person's natural coping style and social support $[11,12]$. Subjects with high SOC assess situations in a more comprehensive way, see life events and health-disease problems as challenges worthy of effort, perceive available resources more easily, and use them to cope with stress when necessary [6]. Previous studies have reported that high SOC was associated with better normative and subjective oral health outcomes $[13,14,30]$. Thus, despite having low social capital, more resilient individuals tend to feel less affected by oral problems, and consequently, present a better OHRQoL.

Our findings also indicated that the negative effects of low social capital on OHRQoL were statistically significant across different levels of SOC in both assessments (baseline and follow-up). However, the greatest moderation effect of SOC was observed in the interaction with social capital at follow-up (crosssectional interaction). Possible explanations for this finding include the assessment of social capital by parents at baseline and by the adolescents at follow up. In addition, social capital may have changed over the time. Parent's social capital may be different from the adolescent's social capital, since social capital may vary according to time, gender, and personal experiences [31]. In addition, since SOC interacts 
with a person's natural coping style and social capital, the extent to which these elements are available is one of the main determinants related to the development of SOC [11]. In this sense, the protective effect provided by the interaction between the social capital reported by adolescents and their SOC on OHRQoL may be more strongly linked in the same stage of life, which is in agreement with our results.

Our findings must be interpreted with caution due to some limitations. First, we assessed social capital through indicators or proxies, which may not give a complete measure of the construct. However, these indicators have been commonly used in previous studies [5,22]. In addition, possible changes of SOC over the study period was not assessed since the construct was only investigated at follow-up. Finally, followup data collection was affected by the COVID-19 pandemic, which may have led to information bias among individuals who were assessed before and during this period. However, sensitivity analysis demonstrated that this issue did not affect our findings. Moreover, postponing data collection for a postpandemic period would possibly result in the modification of the predictors considered in this study that affect the OHRQoL.

Our study also has strengths. This 10-year cohort study had a high retention rate (67.1\%) and was conducted during an important period of life characterized by biopsychosocial development. Studying psychosocial factors from childhood to adolescence is extremely important, as experiences during this stage can be perpetuated throughout life [32,33]. In addition, our study considered important psychosocial conditions, which have been explored in the previous literature [12-15, 34, 35]. A previous cluster-randomized trial demonstrated that a school-based intervention focusing on school environmental changes to enhance children's SOC improved their SOC as well as their OHRQOL [34]. Another pragmatic randomized clinical trial involving older adults proposed a complex intervention to promote social capital, self-management, and health literacy and showed positive effects of the intervention on mental health and health promotion [35].

In this context and based on our findings, further research is needed to evaluate interventions aiming to promote SOC and social capital $[12,34,35]$, and their impact on the subjective health and oral health promotion in different population groups. Furthermore, future research aiming to examine the possible role of other modifying factors of oral health conditions, as well as high-quality trials, especially assessing the sustainability of the intervention effect, is necessary.

\section{Conclusion}

Our findings showed that SOC may have a moderating effect on the relationship between social capital and OHRQOL. Schoolchildren with low social capital and high SOC were protected from having worse OHRQoL compared to individuals with low SOC. This knowledge is useful because it allows the recognition of factors that can reduce the harmful effects of low social capital on OHRQoL.

\section{Abbreviations}


CPQ: Child Perception Questionnaire; OHRQoL: Oral Health-related Quality of Life; BMW, Brazilian minimum wage; WHO: World Health Organization; DMFT: decayed, missing and filling teeth; SD: standard deviation; SE: standard error; SOC: sense of coherence; RR: Rate Ratio; $\mathrm{Cl}$, confidence interval.

\section{Declarations}

\section{Acknowledgements}

The authors thank all the scholars, their parents and schools that took part in this study, as well as the Health and Education Authorities from Santa Maria, Rio Grande do Sul, for all information and authorization

\section{Authors' contributions}

Ms Knorst conceptualized and designed the study, collected data, performed the statistical analyzes, drafted the initial manuscript, and revised the manuscript. Ms Brondani collected data and revised the manuscript. Dr Emmanuelli, Dr Tomazoni and Dr Vettore designed the study and revised the manuscript. Dr Ardenghi designed the study, coordinated and supervised the data collection and critically reviewed the manuscript. All authors have approved the final manuscript and agree to be accountable for all aspects of the paper.

\section{Funding}

This study was funded by the Conselho Nacional de Desenvolvimento Científico e Tecnológico (CNPq process 160258/2020-0) and Fundação de Amparo à Pesquisa do Estado do Rio Grande do Sul (FAPERPGS - process 17/2551-0001083-3).

\section{Ethics approval and consent to participate}

All procedures performed in studies involving human participants were in accordance with the ethical standards of the Human Research Ethics Committee of the Federal University of Santa Maria (protocol number 11765419.1.0000.5346), Brazil. Informed consent was obtained from all individual participants included in the study.

\section{Consent for publication}

Not applicable.

\section{Competing interests}

The authors have no conflicts of interest in relation to the products or methods mentioned herein.

\section{References}


1. Peres MA, Macpherson LMD, Weyant RJ, Daly B, Venturelli R, Mathur MR, Listl S, Celeste RK, Guarnizo-Herreño CC, Kearns C, Benzian H, Allison P, Watt RG. Oral diseases: a global public health challenge. Lancet. 2019 Jul 20;394(10194):249-260.

2. Glick M, Williams DM, Kleinman DV, Vujicic M, Watt RG, Weyant RJ. A new definition for oral health developed by the FDI World Dental Federation opens the door to a universal definition of oral health. Int Dent J. 2016 Dec;66(6):322-324.

3. Sischo L, Broder HL. Oral health-related quality of life: what, why, how, and future implications. J Dent Res. 2011 Nov;90(11):1264-70.

4. Pinheiro SAA, Rodrigues HB, Santos JTL, Granja GL, Lussi A, Leal SC, Diniz MB. Association of dental caries morbidity stages with oral health-related quality of life in children and adolescents. Int $\mathrm{J}$ Paediatr Dent. 2020 May;30(3):293-302.

5. Knorst JK, Sfreddo CS, de F Meira G, Zanatta FB, Vettore MV, Ardenghi TM. Socioeconomic status and oral health-related quality of life: A systematic review and meta-analysis. Community Dent Oral Epidemiol. 2021 Apr;49(2):95-102.

6. Antonovsky A. Unraveling mystery of health: how people manage stress and stay well. San Francisco, CA: Jossey-Bassd, 1987.

7. Moore S, Kawachi I. Twenty years of social capital and health research: a glossary. J Epidemiol Community Health. 2017 May;71(5):513-517.

8. Putnam RD. Making democracy work: civic traditions in modern Italy. Princeton, NJ: Princeton University Press, 1993.

9. Rostila M. The facets of social capital. J Theory Soc Behav. 41(3), 308-326.

10. Rouxel PL, Heilmann A, Aida J, Tsakos G, Watt RG. Social capital: theory, evidence, and implications for oral health. Community Dent Oral Epidemiol. 2015 Apr;43(2):97-105.

11. Gupta E, Robinson PG, Marya CM, Baker SR. Oral Health Inequalities: Relationships between Environmental and Individual Factors. J Dent Res. 2015 Oct;94(10):1362-8.

12. Mato $M$, Tsukasaki K. Factors promoting sense of coherence among university students in urban areas of Japan: individual-level social capital, self-efficacy, and mental health. Glob Health Promot. 2019 Mar;26(1):60-68.

13. da Silva AN, Vettore MV. Sense of coherence modifies the association between untreated dental caries and dental pain in low-social status women. Community Dent Health. 2016 Mar;33(1):54-9.

14. Machado FW, Perroni AP, Nascimento GG, Goettems ML, Boscato N. Does the Sense of Coherence modifies the relationship of oral clinical conditions and Oral Health-Related Quality of Life? Qual Life Res. 2017 Aug;26(8):2181-2187.

15. Qiu C, Shao D, Yao Y, Zhao Y, Zang X. Self-management and psychological resilience moderate the relationships between symptoms and health-related quality of life among patients with hypertension in China. Qual Life Res. 2019 Sep;28(9):2585-2595. 
16. Vettore MV, Ahmad SFH, Machuca C, Fontanini H. Socio-economic status, social support, social network, dental status, and oral health reported outcomes in adolescents. Eur J Oral Sci. 2019 Apr;127(2):139-146.

17. Piovesan C, Ardenghi TM, Guedes RS, Ekstrand KR, Braga MM, Mendes FM. Activity assessment has little impact on caries parameters reduction in epidemiological surveys with preschool children. Community Dent Oral Epidemiol. 2013 Jun;41(3):204-11.

18. World Health Organization. Novel Coronavirus (2019-ncov) Situation Report-22 Situations; WHO, 2020.

19. World Health Organization. Oral Health Surveys: Basic Methods. Vol 1. 4th ed. Geneva: WHO Press: 1997; 1-66.

20. Torres CS, Paiva SM, Vale MP, Pordeus IA, Ramos-Jorge ML, Oliveira AC, Allison PJ. Psychometric properties of the Brazilian version of the Child Perceptions Questionnaire (CPQ11-14) - short forms. Health Qual Life Outcomes. 2009 17;7:43.

21. Menegazzo GR, Knorst JK, Ortiz FR, Tomazoni F, Ardenghi, TM. Evaluation of Psychometric Properties of the 'Sense of Coherence Scale'in Schoolchildren. Interam J Psychol. 2020; 54(1), e1148e1148.

22. Ismail Al, Sohn W, Tellez M, Amaya A, Sen A, Hasson H, Pitts NB. The International Caries Detection and Assessment System (ICDAS): an integrated system for measuring dental caries. Community Dent Oral Epidemiol. 2007 Jun;35(3):170-8.

23. Paxton P. Is social capital declining in the United States? A multiple indicator assessment. Am J Sociol. 1999; 105(1), 88-127.

24. Furuta M, Ekuni D, Takao S, Suzuki E, Morita M, Kawachi I. Social capital and self-rated oral health among young people. Community Dent Oral Epidemiol. 2012 Apr;40(2):97-104.

25. Meira GF, Knorst JK, Maroneze MC, Ortiz FR, Ardenghi TM. Effect of dental caries and socioeconomic status on social capital throughout adolescence: a 6-year follow-up. Braz Oral Res. 2020 Sep 4;34:e104.

26. Instituto Brasileiro de Geografia e Estatística. Censo 2010. Rio de Janiero: IBGE; 2010. Available: http://www.ibge.gov.br/home/estatis tica/populacao/. Accessed June 1,

27. Knol MJ, VanderWeele TJ. Recommendations for presenting analyses of effect modification and interaction. Int J Epidemiol. 2012 Apr;41(2):514-20.

28. Guedes RS, Piovesan C, Antunes JL, Mendes FM, Ardenghi TM. Assessing individual and neighborhood social factors in child oral health-related quality of life: a multilevel analysis. Qual Life Res. 2014 Nov;23(9):2521-30.

29. Kawachi I, Berkman L. Social cohesion, social capital, and health. Social epidemiology. 2000; 174(7), 290-319.

30. Tomazoni F, Vettore MV, Mendes FM, Ardenghi TM. The Association between Sense of Coherence and Dental Caries in Low Social Status Schoolchildren. Caries Res. 2019;53(3):314-321. 
31. McDonald S, Mair CA. Social capital across the life course: Age and gendered patterns of network resources 1. In Sociological Forum(Vol. 25, No. 2, pp. 335-359). Oxford, UK: Blackwell Publishing Ltd, 2010.

32. Holst D, Schuller AA. Oral health in a life-course: birth-cohorts from 1929 to 2006 in Norway. Community Dent Health. 2012 Jun;29(2):134-43.

33. Straatmann VS, Lai E, Lange T, Campbell MC, Wickham S, Andersen AN, Strandberg-Larsen K, TaylorRobinson D. How do early-life factors explain social inequalities in adolescent mental health? Findings from the UK Millennium Cohort Study. J Epidemiol Community Health. 2019 Nov;73(11):1049-1060.

34. Tomazoni F, Vettore MV, Baker SR, Ardenghi TM. Can a School-Based Intervention Improve the Oral Health-Related Quality of Life of Brazilian Children? JDR Clin Trans Res. 2019 Jul;4(3):229-238.

35. Blancafort Alias S, Monteserín Nadal R, Moral I, Roqué Fígols M, Rojano I Luque X, Coll-Planas L. Promoting social capital, self-management and health literacy in older adults through a group-based intervention delivered in low-income urban areas: results of the randomized trial AEQUALIS. BMC Public Health. 2021 Jan 7;21(1):84.

\section{Tables}

Table 1. Demographic, socioeconomic, psychosocial and oral health variables of the sample at baseline (T1) and follow-up (T2) 


\begin{tabular}{|c|c|c|c|}
\hline \multirow[t]{2}{*}{ Variables } & Baseline & Follow-up & p-value \\
\hline & $\mathrm{T} 1(\mathrm{n}=639)$ & T2 $(n=429)$ & \\
\hline \multicolumn{4}{|c|}{ Demographic and socieconomic variables } \\
\hline $\operatorname{Sex}[n(\%)]$ & & & 0.22 \\
\hline Boys & $322(49.0)$ & $209(49.8)$ & \\
\hline Girls & $317(51.0)$ & $220(50.2)$ & \\
\hline Age [mean SE)] & $12.5(0.1)$ & $2.8(0.1)$ & 0.10 \\
\hline Skin color & & & 0.15 \\
\hline White & $501(80.5)$ & $215(48.5)$ & \\
\hline No-white & $137(19.5)$ & $211(51.5)$ & \\
\hline \multicolumn{4}{|c|}{ Household income in BMW [n (\%)] } \\
\hline$\leq 1 \mathrm{BMW}$ & $129(19.0)$ & $110(29.2)$ & \\
\hline$>1 \mathrm{BMW}$ & $473(81.0)$ & $264(70.8)$ & \\
\hline Maternal education [n (\%)] & & & 0.66 \\
\hline$\geq 8$ years & $357(54.3)$ & $285(69.6)$ & \\
\hline$<8$ years & $275(45.7)$ & $110(30.4)$ & \\
\hline \multicolumn{4}{|l|}{ Psychosocial variables } \\
\hline Social capital [n (\%)] & & & 0.47 \\
\hline High & $479(75.6)$ & $315(73.5)$ & \\
\hline Low & $154(24.4)$ & $110(26.5)$ & \\
\hline Sense of choerence [n (\%)] & & & - \\
\hline Low & - & $35(7.9)$ & \\
\hline Middle & & $145(32.6)$ & \\
\hline High & & $249(59.5)$ & \\
\hline \multicolumn{4}{|l|}{ Oral health variables } \\
\hline Untreated dental caries [n (\%)] & & & 0.73 \\
\hline Absent & $408(61.6)$ & $300(69.4)$ & \\
\hline Present & $231(38.4)$ & $128(30.6)$ & \\
\hline CPQ11-14 [mean (SE)] & - & $11.2(0.6)$ & - \\
\hline
\end{tabular}


*Taking into account the sampling weight; Values lower than 639 or 429 are due to missing data. ${ }^{\dagger}$ Comparison between followed and dropouts individuals; BMW, Brazilian minimum wage; SE, standard deviation; $\mathrm{CPQ}$, child perception questionnaire.

Table 2. Unadjusted analysis of the interaction of social capital at T1 and T2 and sense of coherence on overall CPQ11-14 scores at follow-up 


\begin{tabular}{|c|c|c|}
\hline \multirow[t]{2}{*}{ Variables } & \multicolumn{2}{|l|}{ CPQ11-14 } \\
\hline & $\mathrm{RR}(95 \% \mathrm{Cl})$ & p-value \\
\hline \multicolumn{3}{|c|}{ Social capital (T1) } \\
\hline High & 1 (reference) & \\
\hline Low & $1.16(1.08-1.24)$ & $<0.01$ \\
\hline \multicolumn{3}{|c|}{ Social capital (T2) } \\
\hline High & 1 (reference) & \\
\hline Low & $1.09(1.02-1.17)$ & $<0.01$ \\
\hline \multicolumn{3}{|c|}{ Sense of choerence (T2) } \\
\hline Low & 1 (reference) & \\
\hline Middle & $0.70(0.64-0.77)$ & $<0.01$ \\
\hline High & $0.39(0.36-0.46)$ & $<0.01$ \\
\hline \multicolumn{3}{|c|}{ Interaction variables } \\
\hline \multicolumn{3}{|c|}{ Social Capital (T1) x Sense of choerence (T2) } \\
\hline Low\#Low & 1 (reference) & \\
\hline High\#Low & $0.97(0.82-1.14)$ & 0.72 \\
\hline High\#Middle & $0.67(0.58-0.78)$ & $<0.01$ \\
\hline High\#High & $0.38(0.33-0.44)$ & $<0.01$ \\
\hline Low\#Middle & $0.75(0.64-0.88)$ & $<0.01$ \\
\hline Low\#High & $0.38(0.33-0.45)$ & $<0.01$ \\
\hline \multicolumn{3}{|c|}{ Social Capital (T2) x Sense of choerence (T2) } \\
\hline Low\#Low & 1 (reference) & \\
\hline High\#Low & $0.74(0.62-0.87)$ & $<0.01$ \\
\hline High\#Middle & $0.57(0.48-0.66)$ & $<0.01$ \\
\hline High\#High & $0.31(0.26-0.36)$ & $<0.01$ \\
\hline Low\#Middle & $0.57(0.48-0.67)$ & $<0.01$ \\
\hline Low\#High & $0.32(0.27-0.39)$ & $<0.01$ \\
\hline
\end{tabular}

$\mathrm{RR}$, rate ratio; $\mathrm{Cl}$, confidence interval; $\mathrm{T} 1$, baseline; $\mathrm{T} 2$, follow-up. 
Table 3. Adjusted analysis of the interaction of social capital at T1 and T2 and sense of coherence on overall CPQ11-14 scores at follow-up

\begin{tabular}{|lll|}
\hline Interaction variables & CPQ11-14 & \\
\cline { 2 - 3 } & RR (95\% Cl)* & p-value \\
Social Capital (T1) x Sense of choerence (T2) & & \\
Low\#Low & 1 (reference) & \\
High\#Low & $1.04(0.87-1.24)$ & 0.62 \\
High\#Middle & $0.75(0.64-0.87)$ & $<0.01$ \\
High\#High & $0.42(0.35-0.48)$ & $<0.01$ \\
Low\#Middle & $0.78(0.78-0.93)$ & $<0.01$ \\
Low\#High & $0.36(0.30-0.44)$ & $<0.01$ \\
\hline Social Capital (T2) x Sense of choerence (T2) & \\
Low\#Low & $1($ reference) & \\
High\#Low & $0.67(0.56-0.80)$ & $<0.01$ \\
High\#Middle & $0.54(0.46-0.64)$ & $<0.01$ \\
High\#High & $0.29(0.24-0.34)$ & $<0.01$ \\
Low\#Middle & $0.55(0.46-0.66)$ & $<0.01$ \\
Low\#High & $0.30(0.25-0.36)$ & $<0.01$ \\
\hline
\end{tabular}

$\mathrm{RR}$, rate ratio; $\mathrm{Cl}$, confidence interval; $\mathrm{T} 1$, baseline; T2, follow-up; *Adjuested by sex, skin color, age, household income and untreated dental caries.

Table 4. Predictive marginal effects between the social capital and OHRQOL according to different levels of sense of coherence among individuals with low social capital 


\begin{tabular}{|lll|}
\hline \multicolumn{3}{|c|}{ CPQ11-14 } \\
\hline Interaction variables & Margin (95\% Cl) & p-value \\
\hline Low social capital at T1 & \\
\hline Low SOC (Mean - 1xSD) & $19.41(16.92-21.90)$ & $<0.01$ \\
\hline Middle SOC (Mean) & $14.89(13.64-16.13)$ & $<0.01$ \\
\hline High SOC (Mean + 1SD) & $7.76(6.99-8.52)$ & $<0.01$ \\
\hline Low social capital at T2 & & \\
\hline Low SOC (Mean - 1xSD) & $24.25(20.8-27.6)$ & $<0.01$ \\
\hline Middle SOC (Mean) & $13.61(12.5-14.8)$ & $<0.01$ \\
\hline High SOC (Mean + 1SD) & $7.93(7.21-8.65)$ & $<0.01$ \\
\hline
\end{tabular}

SOC, sense of coherence. *dy/dx for factor levels is the discrete change from the base level.

\section{Figures}

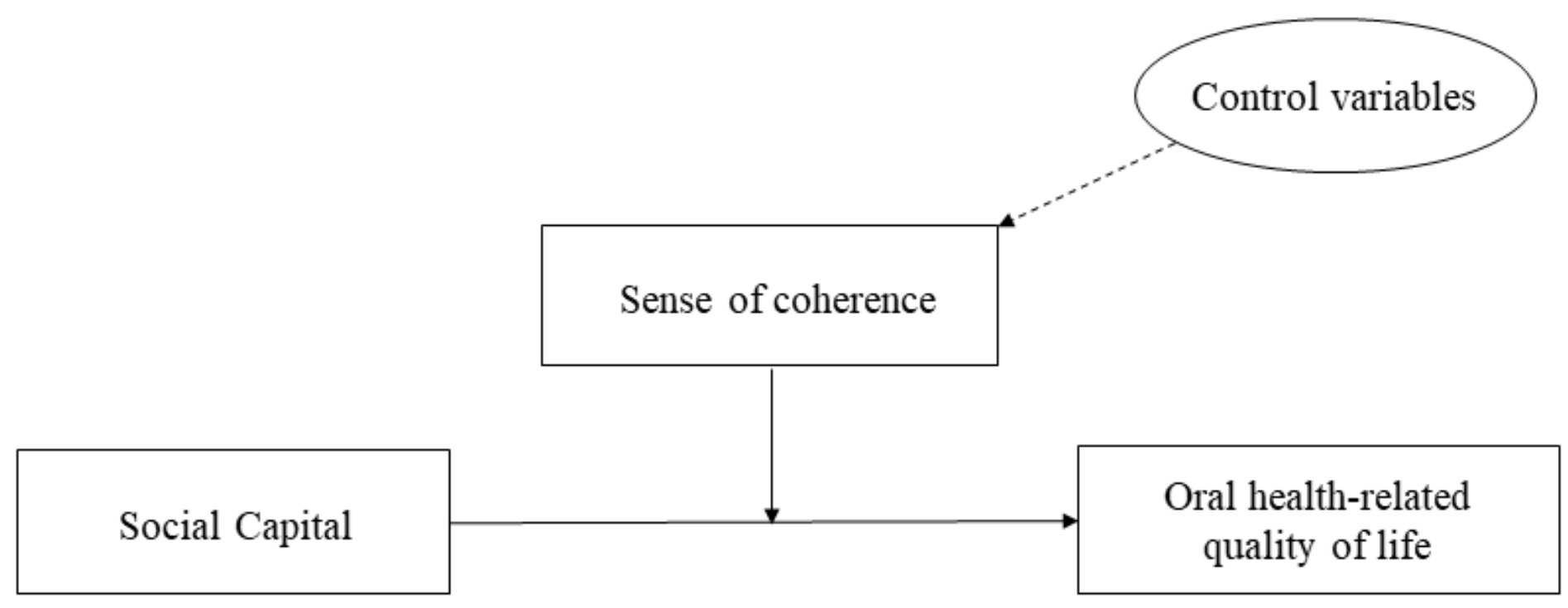

Figure 1 


\section{Predictive Margins with 95\% Cls}

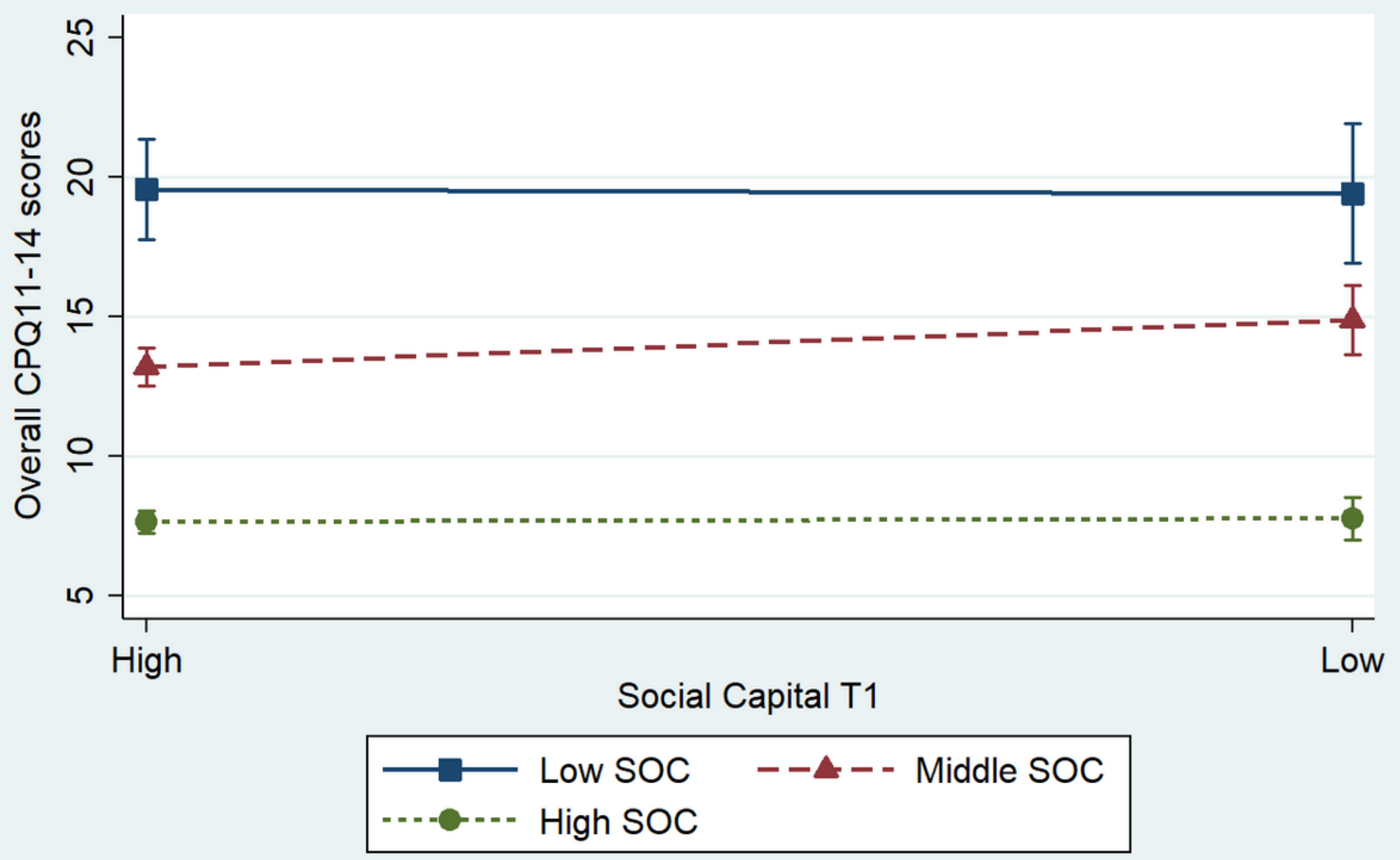

Figure 2

Predictive marginal effects between social capital at baseline and overall CPQ11-14 scores according to different levels of sense of coherence. 


\section{Predictive Margins with $95 \% \mathrm{Cls}$}

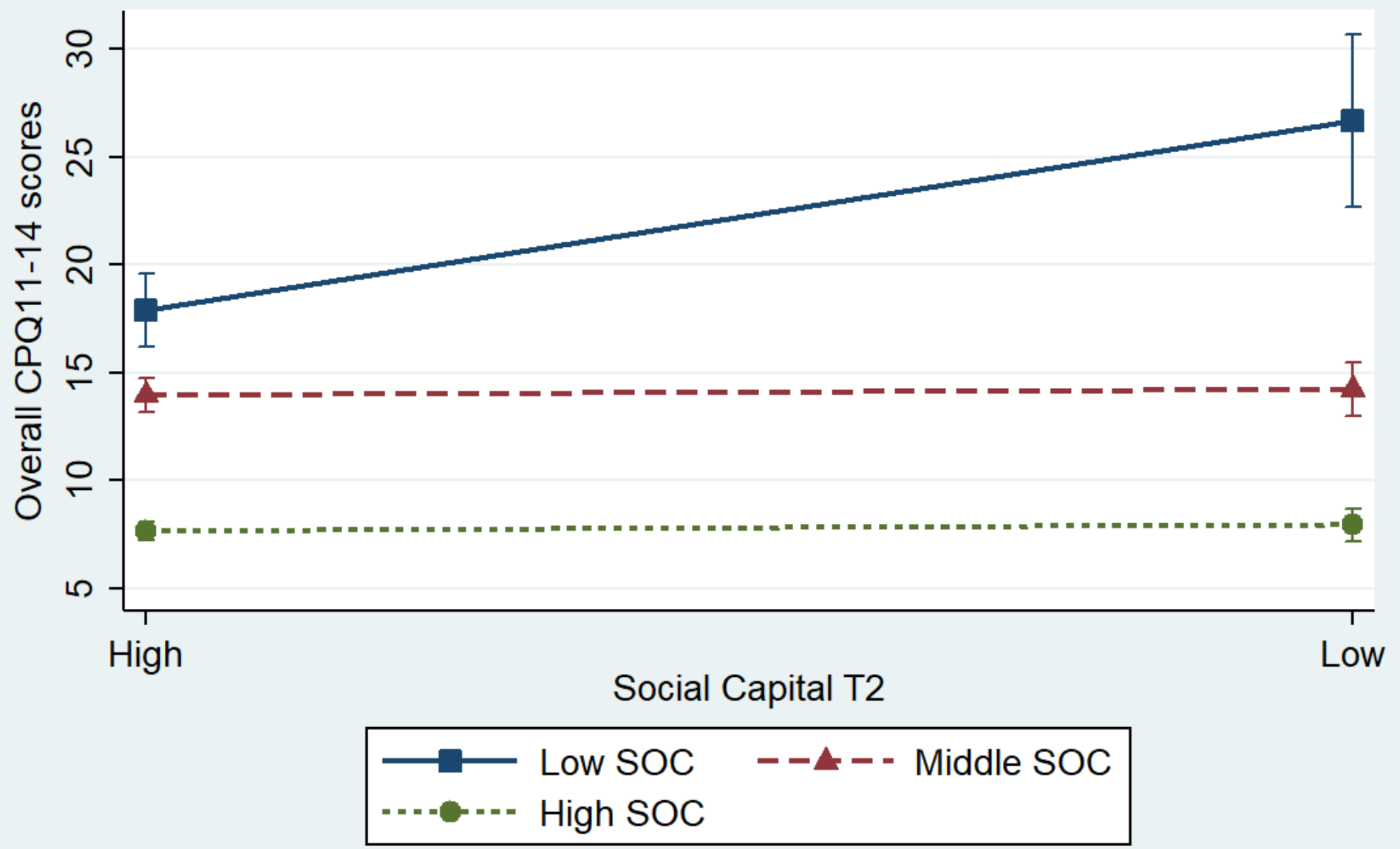

Figure 3

Predictive marginal effects between social capital at follow-up and overall CPQ11-14 scores according to different levels of sense of coherence. 